\title{
EFFECT OF HYDROXAMIC ACIDS FROM CEREALS ON APHID CHOLINESTERASES
}

\author{
Liliana Cuevas and HermanN M. NiEMEyer \\ Departamento de Química, Facultad de Ciencias, Universidad de Chile, Casilla 653, Santiago, Chile
}

(Received 15 March 1993)

Key Word Index - Gramineae; cereals; Rhopalosiphum padi; cereal aphid; hydroxamic acids; cholinesterases; inactivation.

\begin{abstract}
Dihydroxy-7-methoxy-1,4-benzoxazin-3-one (DIMBOA), a hydroxamic acid involved in the resistance of wheat to the aphid Rhopalosiphum padi, and known to react with serine and cysteine residues, inactivated acylcholinesterases (acylcholine hydrolases, EC 3.1.1.7) from homogenates of whole bodies of adult $R$. padi. The enzyme preparation was shown to consist mainly of acetylcholinesterase (AChE) containing an essential cysteine residue outside the substrate binding site. AChE from $R$. padi, and also ChE from other insects and from human erythrocytes which do not possess such a cysteine residue, were inhibited $\left(I_{50}\right.$ in the $m M$ range) by DIMBOA. 4Hydroxy-7-methoxy-1,4-benzoxazin-3-one, a compound known to react with cysteine residues but not with serine residues, did not inactivate $\mathrm{AChE}$ from $R$. padi under similar conditions. The results suggest that inactivation of $\mathrm{AChE}$ from $R$. padi by DIMBOA does not occur through reaction with its characteristic cysteine residue.
\end{abstract}

\section{INTRODUCTION}

Hydroxamic acids $(\mathrm{Hx})$ present in cereals [1], play a major role in the defence of the plants against aphids $[2$, $3]$, through antibiosis $[4,5]$ and antixenosis $[6,7]$. 2,4Dihydroxy-7-methoxy-1,4-benzoxazin-3-one (DIMBOA, 1), the main $\mathrm{Hx}$ in wheat extracts, possesses electrophilic sites responsible for its reactivity towards free nucleophiles [8-10] and also towards enzymes possessing essential nucleophilic residues, e.g. papain [11] and $\alpha$-chymotrypsin [12].

Acetylcholinesterase (AChE) is a key enzyme in the transmission of nerve impulses in mammals and insects $[13,14]$, and the target in insects of organophosphorous and carbamate pesticides [15]. The toxicity of these insecticides resides on their electrophilic centres which react with the nucleophilic serine moiety at the substrate binding site of the enzyme [16]. The similarities between the reactivity of organophosphorous and carbamate insecticides and hydroxamic acids towards nucleophiles, make $\mathrm{AChE}$ an attractive target for the action of these latter compounds. In order to explore this possible mechanism of toxicity of DIMBOA towards aphids, its interaction with AChE from homogenates of Rhopalosiphum padi (L.) was studied.

\section{RESULTS AND DISCUSSION}

Identification and characterization of cholinesterases from homogenates of $\mathbf{R}$. padi

Different substrates and specific inhibitors were employed to distinguish between different cholinesterases<smiles>COc1ccc2c(c1)OC(O)C(=O)N2O</smiles>

1, DIMBOA<smiles>COc1ccc(N(O)C(=O)C=O)c(O)c1</smiles>

2<smiles>COc1ccc2c(c1)OCC(=O)N2O</smiles>

3

present in whole body homogenates of $R$. padi [15-17]. The homogenate hydrolysed acetylthiocholine chloride (AcThCh) at a rate of $0.19 \mu$ moles $\min ^{-1} \mathrm{mg}^{-1}$ protein, butyrylthiocholine chloride (BuThCh) at 0.08 $\mu$ moles $\min ^{-1} \mathrm{mg}^{-1}$ protein and propionylthiocholine chloride (PrThCh) at $0.1 \mu$ moles $\mathrm{min}^{-1} \mathrm{mg}^{-1}$ protein. Enzyme activity was completely inhibited by $10^{-5} \mathrm{M}$ eserine sulphate, indicating that the activity was related 
to cholinesterases [18]. 1,5-bis(4-allyldimethylammoniumphenyl)-Pentan-3-one dibromide (BW284C51), a specific inhibitor of acetylcholinesterase (AChE) activity [19], inhibited at $10 \mu \mathrm{M} 90 \%$ of the enzyme activity with AcThCh as substrate but caused no inhibition with BuThCh or PrThCh as substrates, suggesting that at least $90 \%$ of the activity of the crude extracts may be attributed to AChE. The PrThCh hydrolysing activity was inhibited by $100 \mu \mathrm{M}$ iso-OMPA, a specific inhibitor of pscudocholinesterases [16], to an extent of $80 \%$, confirming the presence of propionylcholinesterase.

AChE from R. padi homogenates showed an optimum $\mathrm{pH}$ of 7 (results not shown), in close resemblance to values between 7 and 7.5 reported for Aphis citricola (van der Goot) [18] and Schizaphis graminum (Rondani) [20], and in contrast to values $c a 8.5$ reported for mammalian cholinesterases [13].

AChE from $R$. padi was inhibited by $p$-chloromercuribenzoic acid (PCMB) $\left(\mathrm{I}_{50}=2 \mu \mathrm{M}\right)$ and 5,5'-dithiobis(2nitro-benzoic acid) (DTNB) $\left(I_{50}=1 \mathrm{mM}\right)$. Inhibition by PCMB was not protected by the substrate AcThCh at concentrations 2.4 or $4.8 \mathrm{mM}$, suggesting that the reacting SH group is not located at the active site. In contrast, AChE from other insects such as Ephestia kuehniella (Zeller), Musca domestica $\mathrm{L}$. and Sitophilus granarius L., and from bovine erythrocytes were insensitive to PCMB (results not shown).

Our results demonstrate that AChE from $R$. padi is significantly different from other cholinesterases, presumably due to differences in the structure of the active surface of these enzymes $[18,20-22]$. Moreover, $\mathrm{AChE}$ in $R$. padi, similarly to that of the aphid Myzus persicae (Sulzer), appears to contain a cysteine residue outside the active site which reacts with SH reagents blocking catalysis of substrate hydrolysis [23].

\section{Effect of DIMBOA on the AChE activity from various sources}

$\mathrm{AChE}$ activity was determined in homogenates of various insect and mammalian tissue in the presence of 1 , 5 or $10 \mathrm{mM}$ DIMBOA. Inactivation of the $\mathrm{AChE}$ activity increased with DIMBOA concentration. All cholinesterases studied were inactivated by DIMBOA (Table 1).
The inactivation of enzymes by DIMBOA has been related to the chemical reactivity of its electrophilic centres towards nucleophilic centres of the enzymes. Thus, DIMBOA reacts with cysteine residues either through its hydroxamic nitrogen atom or through the aldehyde group of the open-chain compound $2[9,24]$, with which it forms an equilibrium mixture in solution [25], and with serine residues in enzymes through the aldehyde group of 2 [12]. Finding that all cholinesterases studied were inactivated by DIMBOA suggests that the cysteine residue present in the aphid cholinesterase is not of paramount importance and that the main reaction of DIMBOA occurs with the serine moiety at the active site. This suggestion was supported by the inability of 4-hydroxy-7-methoxy-1,4-benzoxazin-3-one (3) 10 inactivate the cholinesterase from $R$. padi, under identical experimental conditions to inactivation by DIMBOA. Compound 3 retains a hydroxamic acid function but cannot form aldol $\mathbf{2}$ and hence is not able to generate a reactive aldehyde group.

Our results suggest that it is unlikely that cholinesterases are an important target site for toxicity of DIMBOA to aphids owing to the high concentrations needed for inactivation.

\section{EXPERIMENTAL}

Chemicals and chromatographic media. Biochemical reagents, AChEs from bovine erythrocytes and AChEs from human erythrocytes were from Sigma. Compound 3 was synthesized essentially by described methods [26]. Compound 1 was isolated from ethereal extracts of 6-dayold maize (Zea mays L. cv T129s) seedlings as described [27]. Sephadex G-25M columns were from Pharmacia.

Insects. Insects used were adults of E. kuehniella (Zeller), $M$. domestica L., S. granarius L. and R. padi (L.) taken from standard laboratory cultures. While whole bodies were used of $S$. granarius and $R$. padi, only heads were used of $E$. kuehniella and $M$. domestica. Tissue for experiments was frozen in plastic tubes at $-18^{\circ}$ until used.

Preparation of insect homogenates. Homogenates of frozen tissues were prepared at $4^{\circ}$ in $0.05 \mathrm{M}$ sodium phosphate $\mathrm{pH} 7.5$ containing $0.001 \mathrm{M}$ EDTA. The homogenate was filtered through a single layer of cheesecloth

Table 1. Inactivation of acetylcholinesterases from various sources by DIMBOA

\begin{tabular}{lcrrrr}
\hline & \multicolumn{5}{c}{ Relative activity (\% of maximum activity) } \\
& R. padi & S. granarius & E. kuehniella & M. domestica & Human \\
\hline $\begin{array}{l}\text { Control* } \\
\text { DIMBOA }\end{array}$ & 100 & 100 & 100 & 100 & 100 \\
$\begin{array}{l}1 \mathrm{mM} \\
\text { DIMBOA }\end{array}$ & 78 & 9 & 91 & 96 & 88 \\
$5 \mathrm{mM}$ & 58 & 75 & 83 & 81 & 24 \\
$\begin{array}{l}\text { DIMBOA } \\
10 \mathrm{mM}\end{array}$ & 41 & 71 & 44 & 78 & 12 \\
\end{tabular}

*Specific activities for controls without added inactivator were: $0.019 \mathrm{U} \mathrm{mg}^{-1}$ protein (R. padi), 0.021 (S. granarius), 0.013 (E. kuehniella), 0.20 (M. domestica) and 0.35 (human). 
and the filtrate centrifuged for $3 \mathrm{~min}$ at $1500 \mathrm{~g}$. The supernatants were used as enzyme samples, after filtration through Sephadex G-25M columns eluted with $10 \mathrm{mM}$ Na-Pi buffer pH 7.

Determination of the catalytic activity of cholinesterases. The activity of cholinesterases (ChE) was determined by a variation of the Ellman method [17]. ChE was incubated with acylthiocholine (AThCh) at $37^{\circ}$ for a specified time interval. At the end of this period the enzymatic reaction was stopped with ethanol and the colour developed by addition of DTNB. The absorbance at $412 \mathrm{~nm}$ was determined against a non-enzyme reference. The reaction mixt. consisted of $1.2 \mathrm{mM} \mathrm{AThCh}$ and $30 \mu \mathrm{g}$ of protein from the extracts in $0.05 \mathrm{M}$ sodium phosphate $\mathrm{pH} 7$. When measuring the effect of the SH reagents, DTNB or PCMB, these were added together with the substrate. Protein content was determined by the method of Bradford as described [28].

Inactivation of acetylcholinesterase from insect homogenates by $P C M B$ or $D I M B O A$. The reactions were followed under pseudo-first order conditions with an excess of inactivator. Insect homogenates $(99 \mu \mathrm{g})$ were incubated with 0.2 or $0.02 \mathrm{mM}$ PCMB, or 1,5 or $10 \mathrm{mM}$ DIMBOA. Aliquots were withdrawn from the reaction mixt. after $10 \mathrm{~min}$ and filtered through a Sephadex G-25M column as described [29] in order to eliminate excess inactivator. Enzyme activity was measured in the filtrates according to the assays previously described.

Acknowledgements-This work was supported by the International Program in the Chemical Sciences, the Swedish Agency for Research Cooperation with Developing Countries, and by FONDECYT.

\section{REFERENCES}

1. Niemeyer, H. M. (1988) Phytochemistry 27, 3349.

2. Niemeyer, H. M. (1991) in Aphid-Plant Interactions: Populations to Molecules (Peters, D. C., Webster, J. A. and Chlouber, C. S., eds), p. 101. MP-132, USDA/Agricultural Research Service-Oklahoma State University.

3. Niemeyer, H. M., Givovich, A. and Copaja, S. V. (1993) in Pest Control and Sustainable Agriculture (Corey, S. A., Dall, D. J. and Milne, W. M., eds), p. 37. CSIRO Publications.

4. Thackray, D. J., Wratten, S. D., Edwards, P. J. and Niemeyer, H. M. (1990) Ann. Appl. Biol. 116, 573.

5. Morse, S., Wratten, S. D., Edwards, P. J. and Niemeyer, H. M. (1991) Ann. Appl. Biol. 119, 251.
6. Nicol, D., Copaja, S. V., Wratten, S. D. and Niemeyer, H. M. (1992) Ann. Appl. Biol. 121, 11.

7. Givovich, A. and Niemeyer, H. M. (1991) Ent. Exp. Appl. 59, 79.

8. Niemeyer, H. M., Corcuera, L. J. and Pérez, F. J. (1982) Phytochemistry 21, 2287.

9. Pérez, F. J. and Niemeyer, H. M. (1989) Phytochemistry 24, 2963.

10. Pérez, F. J. and Niemeyer, H. M. (1989) Phytochemistry 28, 1831.

11. Pérez, F. J. and Niemeyer, H. M. (1989) Phytochemistry 28, 1597.

12. Cuevas, L., Niemeyer, H. M. and Pérez, F. J. (1990) Phytochemistry 29, 1429.

13. Massoulié, J. and Bon, S. (1982) Ann. Rev. Neurosci. 5, 57.

14. Taylor, P. (1991) J. Biol. Chem. 266, 4025.

15. O'Brien, R. D. (1978) in Biochemistry of Insects (Rockstein, M., ed.), p. 516. Academic Press, New York.

16. Hoover, D. B. (1980) in Modern Pharmacology (Craig, C. R. and Stitzel, R. E., eds), p. 165. Little, Brown and Co., Boston.

17. Goun, V., Prolnov, I., Baltescu, V., Balavan, G. and Bargu, O. (1978) Analyt. Biochem. 86, 234.

18. Manulis, S., Ishaaya, I. and Perry, A. S. (1981) Pesticide Biochem. Physiol. 15, 267.

19. Austin, L. and Berry, W. K. (1953) Biochem. J. 54, 695.

20. Brestkin, A. P., Maizel, E. B., Moralev, S. N., Novozhilov, K. V. and Sazonova, I. N. (1953) Insect Biochem. 15, 309.

21. Novozhilov, K. V., Brestkin, A. P., Khovanskikh, A. E., Maizel, E. B., Moralev, S. N., Nikanorova, E. V. and Sazonova, I. N. (1989) Insect. Biochem. 19, 15.

22. Brestkin, A. P., Khovanskikh, A. E., Maizel, E. B., Moralev, S. N., Novozhilov, K. V., Sazonova, I. N., Abduvakhabov, A. A., Godovikov, N. N., Kabachnik, M. I., Khaskin, B. A., Mastryukova, T. A. and Shipov, A. E. (1986) Insect Biochem. 16, 701.

23. Smissaert, H. R. (1976) Pesticide Biochem. Physiol. 6, 215.

24. Atkinson, J., Morand, P., Arnason, J. T., Niemeyer, H. M. and Bravo, H. R. (1991) J. Org. Chem. 56, 1788.

25. Copaja, S. V., Bravo, H. R. and Niemeyer, H. M. (1986) J. Org. Chem. 51, 3542.

26. Jernow, J. A. and Rosen, P. (1975) U. S. Patent 3, 862, 180.

27. Queirolo, C. B., Andreo, C. S., Niemeyer, H. M. and Corcuera, L. J. (1983) Phytochemistry 22, 2455.

28. Bradford, M. M. (1977) Analyt. Biochem. 72, 248.

29. Penefsky, H. S. (1977) J. Biol. Chem. 252, 2891. 